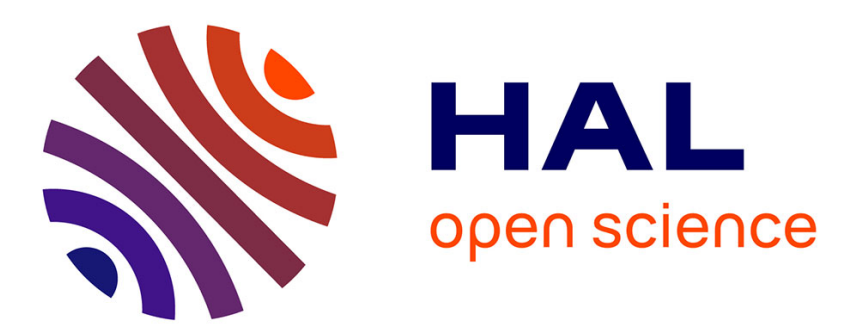

\title{
Nonlinear Controller for Doubly Fed Induction Motor with Bi-Directional AC/DC/AC Converter
}

\author{
Abderrahim Elfadili, Fouad Giri, Abdelmounime El Magri, Luc Dugard
}

\section{To cite this version:}

Abderrahim Elfadili, Fouad Giri, Abdelmounime El Magri, Luc Dugard. Nonlinear Controller for Doubly Fed Induction Motor with Bi-Directional AC/DC/AC Converter. ALCOSP 2013 - 11th IFAC International Workshop on Adaptation and Learning in Control and Signal Processing, Jul 2013, Caen, France. pp.n/c. hal-00818419

\section{HAL Id: hal-00818419 https://hal.science/hal-00818419}

Submitted on 26 Apr 2013

HAL is a multi-disciplinary open access archive for the deposit and dissemination of scientific research documents, whether they are published or not. The documents may come from teaching and research institutions in France or abroad, or from public or private research centers.
L'archive ouverte pluridisciplinaire HAL, est destinée au dépôt et à la diffusion de documents scientifiques de niveau recherche, publiés ou non, émanant des établissements d'enseignement et de recherche français ou étrangers, des laboratoires publics ou privés. 


\title{
Backstepping controller for Doubly Fed Induction Motor with bi-directional $\mathrm{AC} / \mathrm{DC} / \mathrm{AC}$ converter
}

\author{
Abderrahim El Fadili ${ }^{*}$; Fouad Giri ${ }^{1}$; \\ Abdelmounime El Magri ${ }^{1}$. Luc Dugard ${ }^{2}$. \\ ${ }^{1}$ University of Caen Basse-Normandie, CNRS UMR 6072, Caen, \\ France. \\ ${ }^{2}$ University of Grenoble, GIPSA Lab, UMR CNRS, Grenoble-INP, \\ France. \\ *Corresponding authors: elfadili_abderrahim@yahoo.fr
}

\begin{abstract}
This paper deals with the problem of controlling doubly-fed induction machines (DFIM). A nonlinear model of the whole controlled system, including the DFIM and the associated $\mathrm{AC} / \mathrm{DC}$ rectifier and $\mathrm{DC} / \mathrm{AC}$ inverter, is developed within the Park coordinates. A multi-loop nonlinear controller is developed, using the backstepping design technique. The controller is formally shown to meet its objectives i.e. accurate motor speed-reference tracking, tight regulation of the DC Link voltage, power factor correction. The theoretical results are validated by simulation.
\end{abstract}

Keywords: Doubly-fed induction machines (DFIM); AC/DC rectifier; DC/AC inverter; Backstepping design technique; Speed regulation; Power factor correction.

\section{INTRODUCTION}

Nowadays, the Doubly Fed Induction Motor (DFIM) drives are becoming popular in industry applications due to its high power handling capability without increasing the power rating of the converters. It presents good performances stability either in very low speed and in high speed operation Khojet El Khil et al. [2004].

Despite that several studies focused in the study of wind energy conversion systems using doubly fed induction generator (DFIG) (Boukhezzar and Siguerdidjane [2009], Abo-Khalil [2012], Poitiers et al. [2009], Song et al. [2012]), many others propose the use of DFIM in motor application (Metwally et al. [2002], Salloum et al. [2007], Bonnet et al. [2007], Peresadaa et al. [2004], Vidal et al. [2008], Xiying and Jian [2010]), as an interesting alternative, for high power applications such as railway traction, marine propulsion, metallurgy, rolling mills or hydro-electric stations and in very low speed applications like coileruncoiler.

The DFIM drive is a wound rotor AC induction motor can be controlled from the stator or rotor by various possible combinations. Several papers presented various control strategies of DFIM. In Hopfensperger et al. [2000], author's studies a field oriented control without position sensor of DFIM in motor application with one converter in the rotor side where the stator side is connected to the network.

A field oriented control with and without speed sensor of DFIM with tow inverters configuration is presented in (Metwally et al. [2002], Khojet El Khil et al. [2004]). In Gritli et al. [2011] autor's present an original study on fault tolerant control of the DFIM under time-varying conditions. Other control strategies were presented such us direct torque control Bonnet et al. [2007], sliding mode control Vidal et al. [2008], output feedback control Peresadaa et al. [2004] and loop-shaping $H_{\infty}$ control Salloum et al. [2007].

This paper presents a theoretical framework for a global control strategy of the doubly fed induction motor and related power equipments. The DFIM stator windings are directly connected to the line grid, while windings of the wound rotor are controlled by means of a bi-directional power converter. The proposed adaptive backstepping technique control involves a multi-loop nonlinear adaptive controller designed to meet the tow main control objectives i.e. tight speed regulation for a wide range speed-reference variation despite the load torque uncertainly and power factor correction (PFC) for overall DFIM converters. Tools from the averaging theory are resorted to formally describe the control performances.

The paper is organized as follows: in Section 2, the whole association including the $\mathrm{AC} / \mathrm{DC} / \mathrm{AC}$ power conversion and doubly fed induction motor is modeled; the multiobjective controller is designed and analyzed in Section 3; the control performances are illustrated through numerical simulations in Section 4.

\section{MODELLING 'AC/DC/AC CONVERTER-DOUBLY FED INDUCTION MOTOR' ASSOCIATION}

The controlled system is illustrated by Fig. 1. It includes a combination 'doubly fed induction motor-inverter ', on one hand, and a tri-phase $\mathrm{AC} / \mathrm{DC}$ rectifier, on the other 
hand. The rectifier is a $\mathrm{AC} / \mathrm{DC}$ converter operating, like the DC/AC inverter, according to the known Pulse Wide Modulation (PWM) principle.

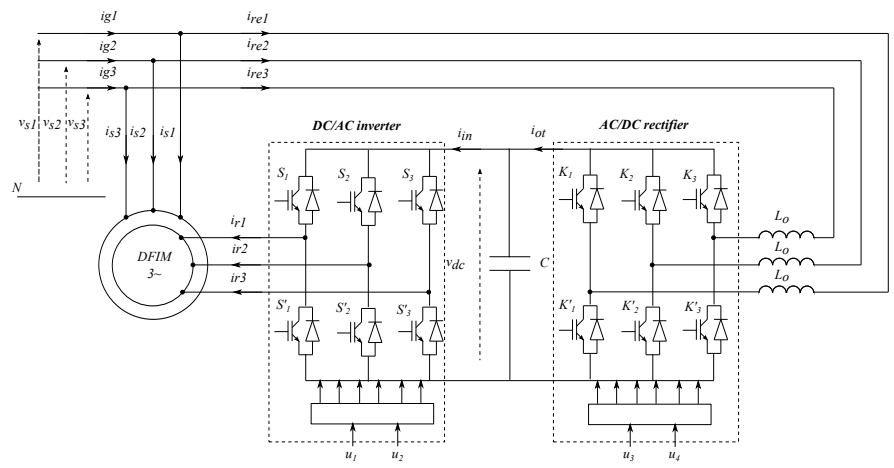

Fig. 1. The AC/DC/AC converter-doubly fed induction motor association

\subsection{Doubly fed induction motor model}

Using the flux $\phi_{s d}, \phi_{s q}$ and current $i_{r d}, i_{r q}$ as state variables and under assumption of linear magnetic circuit, the equivalent two-phase model of the doubly fed induction motor, represented in a rotating reference frame $(d, q)$ linked to the stator voltage is:

$$
\begin{aligned}
\dot{\omega}_{m} & =p \frac{M_{s r}}{J L_{s}}\left(\phi_{s q} i_{r d}-\phi_{s d} i_{r q}\right)-\frac{T_{L}}{J}-\frac{F}{J} \omega_{m} \\
\dot{\phi}_{s d} & =-\frac{1}{\tau_{s}} \phi_{s d}+\omega_{s} \phi_{s q}+\frac{M_{s r}}{\tau_{s}} i_{r d}+V_{s} \\
\dot{\phi}_{s q} & =-\frac{1}{\tau_{s}} \phi_{s q}-\omega_{s} \phi_{s d}+\frac{M_{s r}}{\tau_{s}} i_{r q} \\
\dot{i}_{r d} & =-\gamma_{1} i_{r d}+\left(\omega_{s}-p \omega_{m}\right) i_{r q}+\frac{\gamma_{2}}{\tau_{s}} \phi_{s d} \\
& -p \omega_{m} \gamma_{2} \phi_{s q}-\gamma_{2} V_{s}+\gamma_{3} v_{r d} \\
\dot{i}_{r q} & =-\gamma_{1} i_{r q}-\left(\omega_{s}-p \omega_{m}\right) i_{r d}+\frac{\gamma_{2}}{\tau_{s}} \phi_{s q} \\
& +p \omega_{m} \gamma_{2} \phi_{s d}+\gamma_{3} v_{r q}
\end{aligned}
$$

where $i_{r d}, i_{r q}, \phi_{s d}, \phi_{s q}, \omega_{m}$ and $\omega_{s}$ are the components of rotor currents, stator fluxes, angular speed and Park transformation speed, respectively. Wherever they come in, the subscripts ${ }_{s}$ and ${ }_{r}$ refer to the stator and rotor, respectively. That is, $R_{s}$ and $R_{r}$ are the stator and rotor resistances; $L_{s}$ and $L_{r}$ are the self-inductances; $M_{s r}$ denotes the mutual inductance between the stator and rotor windings; $p$ designates the number of pole-pair, $J$ is the inertia of the motor-load set, $F$ is the friction coefficient and $T_{L}$ is the load torque.

The remaining parameters are defined as follows:

$$
\begin{aligned}
\gamma_{1} & =\frac{R_{r} L_{s}^{2}+R_{s} M_{s r}^{2}}{\sigma L_{r} L_{s}^{2}}, & \sigma=1-\frac{M_{s r}^{2}}{L_{s} L_{r}}, \tau_{s} & =\frac{L_{s}}{R_{s}}, \\
\gamma_{2} & =\frac{M_{s r}}{\sigma L_{s} L_{r}}, & \gamma_{3} & =\frac{1}{\sigma L_{r}}
\end{aligned}
$$

when the stator voltage is linked to the $d$-axis of the frame we have $v_{s d}=V_{s}$ and $v_{s q}=0$, the stator and networks currents will be related directly to the active and reactive power. An adapted control of these currents will thus permit to control the power exchanged between the motor and the grid.

\subsection{Modeling of the combination DFIM DC/AC inverter}

The inverter is featured by the fact that the rotor $d$ - and $q$ voltage can be controlled independently. To this end, these voltages are expressed in function of the corresponding control action see e.g. Michael et al. [1998]:

$$
v_{r d}=v_{d c} u_{1} \quad v_{r q}=v_{d c} u_{2} \quad i_{i n}=u_{1} i_{r d}+u_{2} i_{r q}
$$

where $u_{1}, u_{2}$ represent the average $d$ - and $q$-axis (Park's transformation) of the triphase duty ratio system $\left(s_{1}, s_{2}, s_{3}\right)$, $i_{\text {in }}$ designates the input current inverter and $v_{d c}$ denotes the voltage in capacitor $C$.

$$
\text { With } s_{i}=\left\{\begin{array}{l}
1 \text { if } S_{i} \text { On and } S_{i}^{\prime} \text { Off } \\
0 \text { if } S_{i} \text { Off and } S_{i}^{\prime} \text { On }
\end{array} i=1,2,3\right.
$$

Now, let us introduce the state variables $\bar{\omega}_{m}=x_{1}, \bar{\phi}_{s d}=$ $x_{2}, \bar{\phi}_{s q}=x_{3}, \bar{i}_{r d}=x_{4}, \bar{i}_{r q}=x_{5}, \bar{v}_{d c}=x_{6}, \bar{v}_{r d}=u_{1} x_{6}$, $\bar{v}_{r q}=u_{2} x_{6}$. where $(\bar{\bullet})$ denote the average value on the modulation (MLI) period of $(\bullet)$. Then, substituting (6) in (1-5) yields the following state space representation of the association 'DFIM-inverter':

$$
\begin{aligned}
\dot{x}_{1} & =-\frac{F}{J} x_{1}+p \frac{M_{s r}}{J L_{s}}\left(x_{3} x_{4}-x_{2} x_{5}\right)-\frac{T_{L}}{J} \\
\dot{x}_{2} & =-\frac{1}{\tau_{s}} x_{2}+\omega_{s} x_{3}+\frac{M_{s r}}{\tau_{s}} x_{4}+V_{s} \\
\dot{x}_{3} & =-\frac{1}{\tau_{s}} x_{3}-\omega_{s} x_{2}+\frac{M_{s r}}{\tau_{s}} x_{5} \\
\dot{x}_{4} & =-\gamma_{1} x_{4}+\left(\omega_{s}-p x_{1}\right) x_{5}+\frac{\gamma_{2}}{\tau_{s}} x_{2} \\
& -p \gamma_{2} x_{1} x_{3}-\gamma_{2} V_{s}+\gamma_{3} x_{6} u_{1} \\
\dot{x}_{5} & =-\gamma_{1} x_{5}-\left(\omega_{s}-p x_{1}\right) x_{4}+\frac{\gamma_{2}}{\tau_{s}} x_{3} \\
& +p \gamma_{2} x_{1} x_{2}+\gamma_{3} x_{6} u_{2}
\end{aligned}
$$

\section{3 $A C / D C$ rectifier modeling}

The rectifier circuit (AC/DC) is presented in Fig. 2. The power supply net is connected to a converter which consists of a three phase converter has 6 semiconductors insulated gate bipolar transistors (IGBTs) with anti-parallel diodes for bidirectional current flow mode displayed in three legs 1, 2 and 3 . The 6 semiconductors are considered as ideal switches. Only one switch on the same leg can be conducting at the same time.

Applying Kirchhoff's laws, this subsystem is described by the following set of differential equations:

$$
\begin{aligned}
L_{o} \frac{d\left[i_{r e}\right]_{123}}{d t} & =\left[v_{s}\right]_{123}-v_{d c}[k]_{123} \\
\frac{d v_{d c}}{d t} & =\frac{1}{C}\left(i_{o t}-i_{\text {in }}\right) \\
i_{\text {in }} & =[k]_{123}^{T}\left[i_{r e}\right]_{123}
\end{aligned}
$$

where $\left[i_{r e}\right]_{123}=\left[\begin{array}{lll}i_{r e 1} & i_{r e 2} & i_{r e 3}\end{array}\right]^{T}$ is the input currents in the electric grid (rectifier side), $\left[v_{s}\right]_{123}=\left[\begin{array}{lll}v_{s 1} & v_{s 2} & v_{s 3}\end{array}\right]^{T}$ is the sinusoidal triphase net voltages (with known constant frequency $\left.\omega_{s}\right), i_{o t}$ is the output current rectifier and $k_{i}$ is the switch position function taking values in the discrete set $\{0,1\}$. Specifically:

$$
k_{i}=\left\{\begin{array}{ll}
1 & \text { if } K_{i} \text { On and } K_{i}^{\prime} \text { Off } \\
0 & \text { if } K_{i} \text { Off and } K_{i}^{\prime} \text { On }
\end{array} \quad i=1,2,3\right.
$$




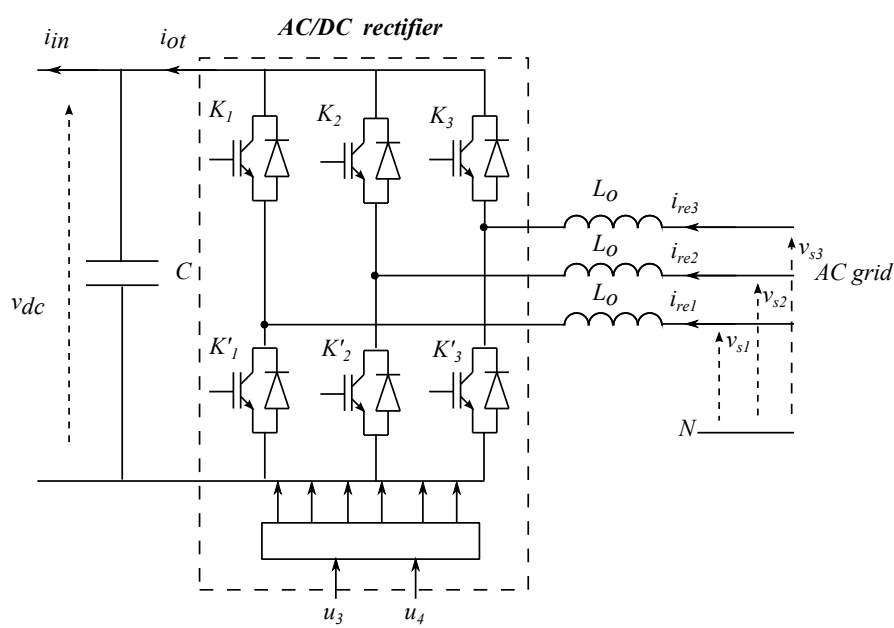

Fig. 2. The AC/DC converter power circuit with a triphase input

To simplify the triphase representation (13 -14) for the synthesis of control laws, the Park transformation, where the $d$-axis of the frame is linked to the stator voltage, is invoked again.

$$
\begin{aligned}
\frac{d i_{r e d}}{d t} & =\omega_{s} i_{r e q}+\frac{V_{s}}{L_{o}}-\frac{v_{d c} u_{3}}{L_{o}} \\
\frac{d i_{r e q}}{d t} & =-\omega_{s} i_{r e d}-\frac{v_{d c} u_{4}}{L_{o}} \\
\frac{d v_{d c}}{d t} & =\frac{1}{C}\left(i_{o t}-i_{i n}\right)
\end{aligned}
$$

where $\left(i_{r e d}, i_{r e q}\right)$ denotes the rectifier side network current in $d q$-coordinates and $u_{3}, u_{4}$ represent the average $d$ - and $q$ - axis components of the triphase duty ratio system $\left(k_{1}\right.$, $\left.k_{2}, k_{3}\right)$.

Let us introduce the state variables $x_{7}=\bar{i}_{r e d}, x_{8}=\bar{i}_{r e q}$, and replacing $i_{o t}$ by $i_{o t}=u_{3} x_{7}+u_{4} x_{8}$. The considered rectifier control design will be based upon the following equations:

$$
\begin{aligned}
& \dot{x}_{6}=\frac{1}{C}\left(u_{3} x_{7}+u_{4} x_{8}-\bar{i}_{i n}\right) \\
& \dot{x}_{7}=\omega_{s} x_{8}+\frac{V_{s}}{L_{o}}-\frac{x_{6} u_{3}}{L_{o}} \\
& \dot{x}_{8}=-\omega_{s} x_{7}-\frac{x_{6} u_{4}}{L_{o}}
\end{aligned}
$$

The state space equations obtained up to now are put together to get a state-space model of the whole system including the $\mathrm{AC} / \mathrm{DC} / \mathrm{AC}$ converters combined with the doubly-fed induction motor (DFIM). For convenience, the whole model is rewritten here for future reference:

$$
\begin{aligned}
\dot{x}_{1} & =-\frac{F}{J} x_{1}+p \frac{M_{s r}}{J L_{s}}\left(x_{3} x_{4}-x_{2} x_{5}\right)-\frac{T_{L}}{J} \\
\dot{x}_{2} & =-\frac{1}{\tau_{s}} x_{2}+\omega_{s} x_{3}+\frac{M_{s r}}{\tau_{s}} x_{4}+V_{s} \\
\dot{x}_{3} & =-\frac{1}{\tau_{s}} x_{3}-\omega_{s} x_{2}+\frac{M_{s r}}{\tau_{s}} x_{5} \\
\dot{x}_{4} & =-\gamma_{1} x_{4}+\left(\omega_{s}-p x_{1}\right) x_{5}+\frac{\gamma_{2}}{\tau_{s}} x_{2}-p \gamma_{2} x_{1} x_{3} \\
& -\gamma_{2} V_{s}+\gamma_{3} x_{6} u_{1} \\
\dot{x}_{5} & =-\gamma_{1} x_{5}-\left(\omega_{s}-p x_{1}\right) x_{4}+\frac{\gamma_{2}}{\tau_{s}} x_{3}+p \gamma_{2} x_{1} x_{2}+\gamma_{3} x_{6} u_{2} \\
\dot{x}_{6} & =\frac{1}{C}\left(x_{7} u_{3}+x_{8} u_{4}-\bar{i}_{i n}\right) \\
\dot{x}_{7} & =\omega_{s} x_{8}+\frac{V_{s}}{L_{o}}-\frac{x_{6} u_{3}}{L_{o}} \\
\dot{x}_{8} & =-\omega_{s} x_{7}-\frac{x_{6} u_{4}}{L_{o}}
\end{aligned}
$$

\section{CONTROLLER DESIGN}

\subsection{Control objectives}

There are two operational control objectives:

(i) Speed regulation: the machine speed $\omega_{m}$ must track, as closely as possible, a given reference signal $x_{1}^{*}$, despite the load torque $T_{L}$ uncertainty.

(ii) PFC requirement: the whole system input current $\left(i_{g 1}, i_{g 2}, i_{g 3}\right)$ must be sinusoidal with the same frequency as the supplied power grid, the reactive power absorbed by DFIM well be all time null.

As there are four control inputs at hand, namely $u_{1}, u_{2}$, $u_{3}$ and $u_{4}$, two more control objectives are added:

(iii) Controlling the continuous voltage $v_{d c}$ making it track a given reference signal $x_{6}^{*}=v_{d c}^{*}$. This generally is set to a constant value equal to the nominal voltage entering the converter and machine.

(iv) Regulating the stator flux norm $\Phi_{s}=\sqrt{x_{2}^{2}+x_{3}^{2}}$ to a reference value $\Phi_{s}^{*}$, preferably equal to its nominal value.

\subsection{Motor speed and stator flux norm regulation}

The problem of controlling the rotor speed and stator flux norm is presently addressed for the doubly fed induction motor described by (23-27). The speed reference $x_{1}^{*}=\omega_{m}^{*}$ is any bounded and derivable function of time and its two first derivatives are available and bounded. These properties can always be achieved filtering the reference through second-order linear filters. The stator flux reference $\Phi_{s}^{*}$ is fixed to its nominal value. The controller design will now be performed in two steps using the tuning-functions adaptive backstepping technique Krstic et al. [1995].

First, introduce the tracking errors:

$$
\begin{aligned}
& z_{1}=x_{1}^{*}-x_{1} \\
& z_{2}=\Phi_{s}^{* 2}-\left(x_{2}{ }^{2}+x_{3}{ }^{2}\right)
\end{aligned}
$$

Step 1. It follows from (23) and (24-25) that the errors $z_{1}$ and $z_{2}$ undergo the differential equations: 


$$
\begin{aligned}
\dot{z}_{1} & =\dot{x}_{1}^{*}+\frac{F}{J} x_{1}-p \frac{M_{s r}}{J L_{s}}\left(x_{3} x_{4}-x_{2} x_{5}\right)+\frac{T_{L}}{J} \\
\dot{z}_{2} & =2 \Phi_{s}^{*} \dot{\Phi}_{s}^{*}-2\left(\dot{x}_{2} x_{2}+\dot{x}_{3} x_{3}\right)-2 x_{2} V_{s} \\
& =2 \Phi_{s}^{*} \dot{\Phi}_{s}^{*}+\frac{2}{\tau_{s}}\left(x_{2}{ }^{2}+x_{3}{ }^{2}\right)-\frac{2 M_{s r}}{\tau_{s}}\left(x_{2} x_{4}+x_{3} x_{5}\right)
\end{aligned}
$$

In (33) and (34), the quantities $p \frac{M_{s r}}{J L_{s}}\left(x_{3} x_{4}-x_{2} x_{5}\right)$ and $\frac{2 M_{s r}}{\tau_{s}}\left(x_{2} x_{4}+x_{3} x_{5}\right)$ stand up as virtual control signals. If these were the actual control signals, the error system (33)(34) could be globally asymptotically stabilized letting $p \frac{M_{s r}}{J L_{s}}\left(x_{3} x_{4}-x_{2} x_{5}\right)=\mu_{1}$ and $\frac{2 M_{s r}}{\tau_{s}}\left(x_{2} x_{4}+x_{3} x_{5}\right)=\nu_{1}$ with:

$$
\begin{aligned}
& \mu_{1} \stackrel{\text { def }}{=} c_{1} z_{1}+\dot{x}_{1}^{*}+\frac{F}{J} x_{1}+\frac{T_{L}}{J} \\
& \nu_{1} \stackrel{\text { def }}{=} c_{2} z_{2}+2 \Phi_{s}^{*} \dot{\Phi}_{s}^{*}+\frac{2}{\tau_{s}}\left(x_{2}^{2}+x_{3}^{2}\right)-2 x_{2} V_{s}
\end{aligned}
$$

On the other hand, the load torque $T_{L}$ is unknown suggests the certainty equivalence from of equations (35).

$$
\mu_{1} \stackrel{\text { def }}{=} c_{1} z_{1}+\dot{x}_{1}^{*}+\frac{F}{J} x_{1}+\frac{\hat{T}_{L}}{J}
$$

where $c_{1}$ and $c_{2}$ are any positive design parameters and $\hat{T}_{L}$ is the estimate of $T_{L}$.

As the quantities $p \frac{M_{s r}}{J L_{s}}\left(x_{3} x_{4}-x_{2} x_{5}\right)=\mu_{1}$ and $\frac{2 M_{s r}}{\tau_{s}}\left(x_{2} x_{4}+\right.$ $\left.x_{3} x_{5}\right)=\nu_{1}$ are not the actual control signals, they cannot be let equal to $\mu_{1}$ and $\nu_{1}$, respectively. Nevertheless, we retain the expressions of $\mu_{1}$ and $\nu_{1}$ as first stabilizing functions and introduce the new errors:

$$
\begin{aligned}
& z_{3}=\mu_{1}-p \frac{M_{s r}}{J L_{s}}\left(x_{3} x_{4}-x_{2} x_{5}\right) \\
& z_{4}=\nu_{1}-\frac{2 M_{s r}}{\tau_{s}}\left(x_{2} x_{4}+x_{3} x_{5}\right)
\end{aligned}
$$

Then, using the notations (37) to (39), the dynamics of the errors $z_{1}$ and $z_{2}$, initially described by (33) - (34), can be rewritten as follows:

$$
\begin{aligned}
& \dot{z}_{1}=-c_{1} z_{1}+z_{3}+\frac{\tilde{T}_{L}}{J} \\
& \dot{z}_{2}=-c_{2} z_{2}+z_{4}
\end{aligned}
$$

where

$$
\tilde{T}_{L}=T_{L}-\hat{T}_{L}
$$

Step 2. The second design step consists in choosing the actual control signals, $u_{1}$ and $u_{2}$, so that all errors $\left(z_{1}, z_{2}\right.$, $\left.z_{3}, z_{4}\right)$ converge to zero. To this end, we should make how these errors depend on the actual control signals $\left(u_{1}, u_{2}\right)$. We start focusing on $z_{3}$; it follows from (38) that:

$$
\dot{z}_{3}=\dot{\mu}_{1}-p \frac{M_{s r}}{J L_{s}}\left(\dot{x}_{3} x_{4}+x_{3} \dot{x}_{4}-\dot{x}_{2} x_{5}-x_{2} \dot{x}_{5}\right)
$$

Assume that the load torque $T_{L}$ is constant or slowly timevarying and using (23-27), (42) and (37), one gets from (43):

$$
\dot{z}_{3}=\mu_{2}+\left(c_{1}-\frac{F}{J}\right) \frac{\tilde{T}_{L}}{J}-\frac{\dot{\tilde{T}}_{L}}{J}-p \frac{M_{s r}}{J L_{s}} \gamma_{3} x_{6}\left(x_{3} u_{1}-x_{2} u_{2}\right)
$$

with

$$
\begin{aligned}
\mu_{2} & =-c_{1}^{2} z_{1}+c_{1} z_{3}+\ddot{x}_{1}^{*}-\left(\frac{F}{J}\right)^{2} x_{1} \\
& +p \frac{M_{s r}}{J L_{s}}\left(\frac{F}{J}+\gamma_{1}+\frac{1}{\tau_{s}}\right)\left(x_{3} x_{4}-x_{2} x_{5}\right)-\frac{F}{J} \frac{\hat{T}_{L}}{J} \\
& +p \frac{M_{s r}}{J L_{s}}\left[p x_{1}\left(x_{3} x_{5}+x_{2} x_{4}\right) p \gamma_{2} x_{1} \Phi_{s}^{2}+\left(\gamma_{2} x_{3}+x_{5}\right) V_{s}\right]
\end{aligned}
$$

Similarly, it follows from (39) that, $z_{4}$ undergoes the following differential equation:

$$
\dot{z}_{4}=\dot{\nu}_{1}-\frac{2 M_{s r}}{\tau_{s}}\left(\dot{x}_{2} x_{4}+x_{2} \dot{x}_{4}+\dot{x}_{3} x_{5}+x_{3} \dot{x}_{5}\right)
$$

Using (23-27) and (36), it follows from (46):

$$
\dot{z}_{4}=\nu_{2}-\frac{2 M_{s r}}{\tau_{s}} \gamma_{3} x_{6}\left(x_{2} u_{1}+x_{3} u_{2}\right)
$$

with

$$
\begin{aligned}
& \nu_{2}=c_{2}\left(-c_{2} z_{2}+z_{4}\right)+2\left(\dot{\Phi}_{s}^{*}\right)^{2}+2 \Phi_{s}^{*} \ddot{\Phi}_{s}^{*} \\
& +2 \frac{M_{s r}}{\tau_{s}}\left(\frac{3}{\tau_{s}}+\gamma_{1}\right)\left(x_{2} x_{4}+x_{3} x_{5}\right)+\frac{4}{\tau_{s}}\left(-\frac{1}{\tau_{s}} \Phi_{s}^{2}+V_{s} x_{2}\right) \\
& -2 V_{s}\left(-\frac{1}{\tau_{s}} x_{2}+\omega_{s} x_{3}+\frac{M_{s r}}{\tau_{s}} x_{4}+V_{s}\right)-2\left(\frac{M_{s r}}{\tau_{s}}\right)^{2}\left(x_{4}^{2}+x_{5}^{2}\right) \\
& -2 \frac{M_{s r}}{\tau_{s}}\left(\frac{\gamma_{2}}{\tau_{s}} \Phi_{s}^{2}+p x_{1}\left(x_{3} x_{4}-x_{2} x_{5}\right)+x_{4} V_{s}-\gamma_{2} x_{2} V_{s}\right)
\end{aligned}
$$

To analyze the error system, composed of equations (40$41),(44)$ and (47), let us consider the following augmented Lyapunov function candidate:

$$
V=\frac{1}{2} z_{1}^{2}+\frac{1}{2} z_{2}^{2}+\frac{1}{2} z_{3}^{2}+\frac{1}{2} z_{4}^{2}+\frac{1}{2} \frac{\tilde{T}_{L}^{2}}{J}
$$

Its time-derivative along the trajectory of the state vector $\left(z_{1}, z_{2}, z_{3}, z_{4}\right)$ is:

$$
\dot{V}=\dot{z}_{1} z_{1}+\dot{z}_{2} z_{2}+\dot{z}_{3} z_{3}+\dot{z}_{4} z_{4}+\frac{\dot{\tilde{T}}_{L} \tilde{T}_{L}}{J}
$$

Using (40-41), (44) and (47), equation (50) implies:

$$
\begin{aligned}
& \dot{V}=z_{1}\left(-c_{1} z_{1}+z_{3}+\frac{\tilde{T}_{L}}{J}\right)+z_{2}\left(-c_{2} z_{2}+z_{4}\right) \\
& +z_{3}\left(\mu_{2}+\left(c_{1}-\frac{F}{J}\right) \frac{\tilde{T}_{L}}{J}-\frac{\dot{\tilde{T}}_{L}}{J}-p \frac{M_{s r}}{J L_{s}} \gamma_{3} x_{6}\left(x_{3} u_{1}-x_{2} u_{2}\right)\right) \\
& +z_{4}\left(\nu_{2}-\frac{2 M_{s r}}{\tau_{s}} \gamma_{3} x_{6}\left(x_{2} u_{1}+x_{3} u_{2}\right)\right)+\frac{\dot{\tilde{T}}_{L} \tilde{T}_{L}}{J}
\end{aligned}
$$

adding $c_{3} z_{3}^{2}-c_{3} z_{3}^{2}+c_{4} z_{4}^{2}-c_{4} z_{4}^{2}$ to the right side of (51) and rearranging terms, yields:

$$
\begin{aligned}
\dot{V} & =-c_{1} z_{1}^{2}-c_{2} z_{2}^{2}-c_{3} z_{3}^{2}-c_{4} z_{4}^{2} \\
& +z_{3}\left[\mu_{2}+c_{3} z_{3}+z_{1}-\frac{\dot{\tilde{T}}_{L}}{J}-p \frac{M_{s r}}{J L_{s}} \gamma_{3} x_{6}\left(x_{3} u_{1}-x_{2} u_{2}\right)\right] \\
& +z_{4}\left[\nu_{2}+c_{4} z_{4}+z_{2}-\frac{2 M_{s r}}{\tau_{s}} \gamma_{3} x_{6}\left(x_{2} u_{1}+x_{3} u_{2}\right)\right] \\
& +\frac{\tilde{T}_{L}}{J}\left[\left(c_{1}-\frac{F}{J}\right) z_{3}+z_{1}+\dot{\tilde{T}}_{L}\right]
\end{aligned}
$$


suggest the following parameter adaptation law:

$$
\dot{\tilde{T}}_{L}=-\left(c_{1}-\frac{F}{J}\right) z_{3}-z_{1}
$$

from (42) and (53), the expression of $\hat{T}_{L}$ can be calculated with the following equation:

$$
\dot{\hat{T}}_{L}=\left(c_{1}-\frac{F}{J}\right) z_{3}+z_{1}
$$

Substituting the parameter adaptation law (53) to $\dot{\tilde{T}}_{L}$ in the right side of (52) yields:

$$
\begin{aligned}
\dot{V} & =-c_{1} z_{1}^{2}-c_{2} z_{2}^{2}-c_{3} z_{3}^{2}-c_{4} z_{4}^{2} \\
& +z_{3}\left[\mu_{2}+\left(c_{3}+\frac{1}{J}\left(c_{1}-\frac{F}{J}\right)\right) z_{3}+\left(1+\frac{1}{J}\right) z_{1}\right] \\
& -z_{3}\left[p \frac{M_{s r}}{J L_{s}} \gamma_{3} x_{6}\left(x_{3} u_{1}-x_{2} u_{2}\right)\right] \\
& +z_{4}\left[\nu_{2}+c_{4} z_{4}+z_{2}-\frac{2 M_{s r}}{\tau_{s}} \gamma_{3} x_{6}\left(x_{2} u_{1}+x_{3} u_{2}\right)\right]
\end{aligned}
$$

where $c_{3}$ and $c_{4}$ are new positive real design parameters. Equation (55) suggests that the control signals $u_{1}, u_{2}$ must be chosen so that the two quantities between curly brackets (on the right side of (55) are set to zero. Letting these quantities equal to zero and solving the resulting secondorder linear equation system with respect to $\left(u_{1}, u_{2}\right)$, gives the following control law:

$$
\left[\begin{array}{l}
u_{1} \\
u_{2}
\end{array}\right]=\Lambda^{-1}\left[\begin{array}{c}
\mu_{2}+\left(c_{3}+\frac{1}{J}\left(c_{1}-\frac{F}{J}\right)\right) z_{3}+\left(1+\frac{1}{J}\right) z_{1} \\
\nu_{2}+z_{2}+c_{4} z_{4}
\end{array}\right]
$$

with:

$$
\begin{array}{rlrl}
\Lambda & =\left[\begin{array}{ll}
\lambda_{0} & \lambda_{1} \\
\lambda_{2} & \lambda_{3}
\end{array}\right] ; & \lambda_{0}=p \frac{M_{s r}}{J L_{s}} \gamma_{3} x_{6} x_{3}, \\
\lambda_{1} & =-p \frac{M_{s r}}{J L_{s}} \gamma_{3} x_{6} x_{2} \\
\lambda_{2} & =\frac{2 M_{s r}}{\tau_{s}} \gamma_{3} x_{6} x_{2}, & \lambda_{3} & =\frac{2 M_{s r}}{\tau_{s}} \gamma_{3} x_{6} x_{3}
\end{array}
$$

It worth's noting that the matrix $\Lambda$ is nonsingular. Indeed, it is easily checked that its determinant is $D=\lambda_{0} \lambda_{3}-$ $\lambda_{2} \lambda_{4}=2 p \frac{M_{s r}^{2}}{J L_{s} \tau_{s}} \gamma_{3}^{2} x_{6}^{2}\left(x_{2}^{2}+x_{3}^{2}\right)$ and $\Phi_{s}=\sqrt{\left(x_{2}^{2}+x_{3}^{2}\right)}$ never vanish in practice because of the machine nonzero remnant flux.

Substituting the control law $(56)$ to $\left(u_{1}, u_{2}\right)$ on the right side of (55) yields:

$$
\dot{V}=-c_{1} z_{1}^{2}-c_{2} z_{2}^{2}-c_{3} z_{3}^{2}-c_{4} z_{4}^{2}
$$

As the right side of (58) is a negative definite function of the state vector $\left(z_{1}, z_{2}, z_{3}, z_{4}\right)$, the closed-loop system is globally asymptotically stable Khalil [2003]. The result thus established is more precisely formulated in the following proposition:

Proposition 1. (Speed regulation). Consider the closedloop system composed of the doubly fed induction motorDC/AC inverter, described by model (23-27), the nonlinear controller defined by the control law (56) and the parameter update law (54). Then, one has the following properties:

1) The closed-loop error system undergoes, in the $\left(z_{1}\right.$, $\left.z_{2}, z_{3}, z_{4}\right)$ coordinates, the following equations:

$$
\begin{aligned}
& \dot{z}_{1}=-c_{1} z_{1}+z_{3}+\frac{\tilde{T}_{L}}{J} \\
& \dot{z}_{2}=-c_{2} z_{2}+z_{4} \\
& \dot{z}_{3}=-c_{3} z_{3}-z_{1}+\left(c_{1}-\frac{F}{J}\right) \frac{\tilde{T}_{L}}{J} \\
& \dot{z}_{4}=-c_{4} z_{4}-z_{2}
\end{aligned}
$$

2) The above linear system is globally asymptotically stable with respect to the Lyapunov function $V=$ $\frac{1}{2} z_{1}^{2}+\frac{1}{2} z_{2}^{2}+\frac{1}{2} z_{3}^{2}+\frac{1}{2} z_{4}^{2}+\frac{1}{2} \frac{\tilde{T}_{L}^{2}}{J}$. Consequently, the errors $\left(z_{1}, z_{2}, z_{3}, z_{4}\right)$ vanish exponentially fast, whatever the initial conditions.

Proof. Equations (59-60) are immediately obtained from (40-41). Equation (61) is obtained substituting the control law $(56)$ and the parameter update law $(54)$ to $\left(u_{1}, u_{2}\right)$ on the right side of (44). Equation (62) is obtained substituting the control law $(56)$ to $\left(u_{1}, u_{2}\right)$ on the right side of $(47)$. This proves Part 1 . On the other hand, it is readily seen from (49) and (53) that $V=\frac{1}{2} z_{1}^{2}+\frac{1}{2} z_{2}^{2}+\frac{1}{2} z_{3}^{2}+\frac{1}{2} z_{4}^{2}+\frac{1}{2} \frac{\tilde{T}_{L}^{2}}{J}$ is a Lyapunov function of the error system (59-62). As $\dot{V}$ is a negative definite function of the state vector $\left(z_{1}, z_{2}, z_{3}\right.$, $z_{4}$ ), the error system is globally asymptotically stable. But asymptotic stability implies exponential stability due to system linearity Khalil [2003]. Proposition 1 is established. Remark 1. . Note that the exponential nature of stability guarantees stability robustness with respect to modelling and measurements errors Khalil [2003].

\subsection{Power factor correction and DC voltage controller}

Controlling rectifier input current to meet PFC: The PFC objective means that the input current overall system should be sinusoidal and in phase with the AC supply voltage.

Therefore, one seeks a regulator that enforces the current $\bar{i}_{g q}=\bar{i}_{s q}+\bar{i}_{r e q}$ to tack a reference signal equal to zero to impose a $i_{g}$ in phase with the voltage supply $v_{s}$.

As the reference signal $\bar{i}_{g q}^{*}$ is null, it follows that the tracking error $z_{5}=\bar{i}_{g q}^{*}-\bar{i}_{g q}$ undergoes the equation:

$$
z_{5}=-\bar{i}_{s q}-x_{8}
$$

as $x_{3}=L_{s} i_{s q}+M_{s r} x_{5}$, equation (63) becomes :

$$
z_{5}=-\frac{x_{3}}{L_{s}}+\frac{M_{s r}}{L_{s}} x_{5}-x_{8}
$$

In view of (25), (27) and (30), the above error undergoes the following equation:

$$
\begin{aligned}
\dot{z}_{5} & =-\frac{\dot{x}_{3}}{L_{s}}+\frac{M_{s r}}{L_{s}} \dot{x}_{5}-\dot{x}_{8} \\
& =-\frac{1}{L_{s}}\left(-\frac{1}{\tau_{s}} x_{3}-\omega_{s} x_{2}+\left(\frac{M_{s r}}{\tau_{s}}+M_{s r} \gamma_{1}\right) x_{5}\right) \\
& +\omega_{s} x_{7}+\frac{x_{6} u_{4}}{L_{o}} \\
& +\frac{M_{s r}}{L_{s}}\left(-\left(\omega_{s}-p x_{1}\right) x_{4}+\frac{\gamma_{2}}{\tau_{s}} x_{3}+p \gamma_{2} x_{1} x_{2}+\gamma_{3} x_{6} u_{2}\right)
\end{aligned}
$$

To get a stabilizing control law for this first-order system, consider the quadratic Lyapunov function $V_{5}=0.5 z_{5}^{2}$. It can be easily checked that the time-derivative $\dot{V}_{5}$ is a 
negative definite function of $z_{5}$ if the control input $u_{4} x_{6}$ is chosen as follows:

$$
u_{4} x_{6}=-c_{5} L_{o} z_{5}-L_{o} \omega_{s} x_{7}+h_{1}(x)
$$

with $c_{5}>0$ is a design parameter and

$$
\begin{aligned}
& h_{1}(x)=\frac{L_{o}}{L_{s}}\left(-\frac{1}{\tau_{s}} x_{3}-\omega_{s} x_{2}+\left(\frac{M_{s r}}{\tau_{s}}+M_{s r} \gamma_{1}\right) x_{5}\right) \\
& +\frac{L_{o} M_{s r}}{L_{s}}\left(\left(\omega_{s}-p x_{1}\right) x_{4}-\frac{\gamma_{2}}{\tau_{s}} x_{3}-p \gamma_{2} x_{1} x_{2}-\gamma_{3} x_{6} u_{2}\right)
\end{aligned}
$$

DC link voltage regulation: The aim is now to design a control law $u_{3}$ so that the rectifier output voltage $x_{6}=\bar{v}_{d c}$ is steered to a given reference value $x_{6}^{*}=v_{d c}^{*}$. As mentioned above, $v_{d c}^{*}$ is generally (not mandatory) set to the nominal value of the rotor voltage amplitude.

Therefore, one seeks a regulator that enforces the current $x_{7}$ to tack a reference signal $x_{7}^{*}$. Introduce the current tracking error $z_{7}$ :

$$
z_{7}=x_{7}^{*}-x_{7}
$$

the $z_{7}$-dynamics undergoes the following equation:

$$
\dot{z}_{7}=\dot{x}_{7}^{*}-\omega_{s} x_{8}-\frac{V_{s}}{L_{o}}+\frac{x_{6} u_{3}}{L_{o}}
$$

To get a stabilizing control signal for this first-order system, consider the following quadratic Lyapunov function:

$$
V_{7}=\frac{1}{2} z_{7}^{2}
$$

It is easily checked that the time-derivative $\dot{V}_{7}$ can be made negative definite in the state $z_{7}$ by letting the quantity $x_{6} u_{3}$ as follows:

$$
x_{6} u_{3}=-c_{7} L_{o} x_{7}^{*}+c_{7} L_{o} x_{7}-L_{o} \dot{x}_{7}^{*}+L_{o} \omega_{s} x_{8}+V_{s}
$$

with $c_{7}>0$ is a design parameter.

Multiply both sides of the equation (28) by $2 x_{6}$ and replace the quantities $x_{6} u_{3}$ and $x_{6} u_{4}$ by their equivalents, described by the equations (71) and (66) respectively, in the equation $(28)$. The squared voltage $\left(y=x_{6}^{2}\right)$ varies, in response to the tuning $x_{7}^{*}$, according to the equation:

$$
\begin{aligned}
\dot{y} & =\frac{2}{C}\left(x_{7} x_{6} u_{3}+x_{8} x_{6} u_{4}-x_{6} \bar{i}_{i n}\right) \\
& =-\frac{2}{C}\left(c_{7} L_{o} x_{7} x_{7}^{*}+L_{o} x_{7} \dot{x}_{7}^{*}+c_{5} L_{o} x_{8} z_{5}\right)+h_{2}(x)
\end{aligned}
$$

where

$$
h_{2}(x)=\frac{2}{C}\left(c_{7} L_{o} x_{7}^{2}+V_{s} x_{7}+x_{8} h_{1}(x)-x_{6} \bar{i}_{i n}\right)
$$

As previously mentioned, the reference signal $y^{*}=v_{d c}^{* 2}$ (of the squared DC-link voltage $x_{6}=v_{d c}$ ) is chosen to be constant (i.e. $\dot{y}^{*}=0$ ), it is given the nominal value of rotor voltage amplitude. Then, it follows from (72) that the tracking error $z_{6}=y^{*}-y$ undergoes the following equation:

$$
\dot{z}_{6}=\dot{y}^{*}+\frac{2}{C}\left(c_{7} L_{o} x_{7} x_{7}^{*}+L_{o} x_{7} \dot{x}_{7}^{*}+c_{5} L_{o} x_{8} z_{5}\right)-h_{2}(x)
$$

To get a stabilizing control law for the system (74), consider the following quadratic Lyapunov function:

$$
V_{6}=\frac{1}{2} z_{6}^{2}
$$

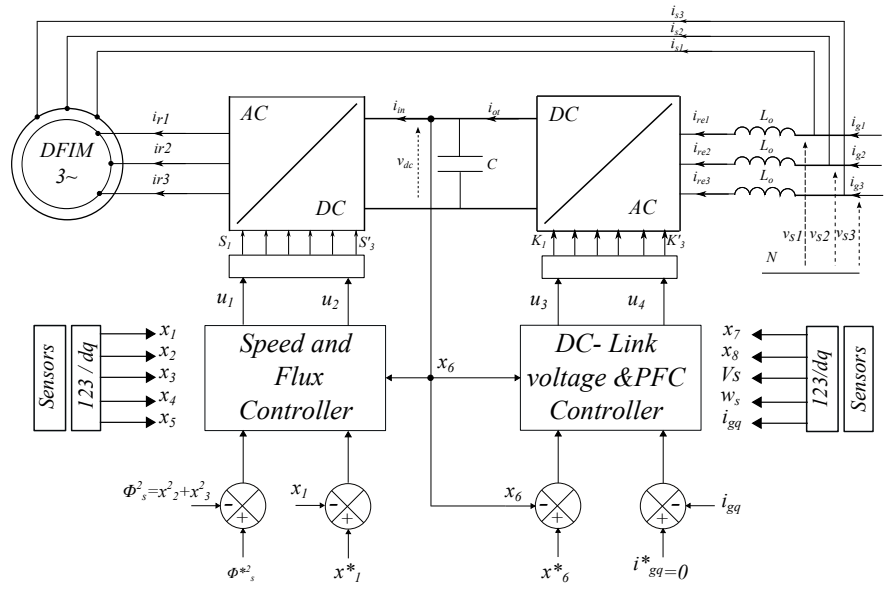

Fig. 3. Control system including $\mathrm{AC} / \mathrm{DC} / \mathrm{AC}$ converters and a doubly- fed induction motor

Deriving $V_{6}$ along the trajectory of (74) yields:

$$
\dot{V}_{6}=\dot{z}_{6} z_{6}
$$

This suggests for $x_{7}^{*}$ the following control law:

$$
\dot{x}_{7}^{*}=-c_{7} x_{7}^{*}-c_{5} z_{5} \frac{x_{8}}{x_{7}}+\frac{C}{2 L_{o} x_{7}}\left(-c_{6} z_{6}-\dot{y}^{*}+h_{2}(x)\right)
$$

with $c_{6}>0$ a design parameter. Indeed, substituting $x_{7}^{*}$ to $(76)$ gives $\dot{V}_{6}=-c_{6} z_{6}^{2}$ which clearly is negative definite in $z_{6}$.

Proposition 2. Consider the control system consisting of the subsystem (28-30) and the control laws (66), (71) and (77). The resulting closed-loop system undergoes, in the $\left(z_{5}, z_{6}, z_{7}, x_{7}^{*}\right)$-coordinates, the following equation:

$$
\dot{Z}=A Z+g(x)
$$

with

$$
\begin{gathered}
Z=\left[\begin{array}{l}
z_{5} \\
z_{6} \\
z_{7} \\
x_{7}^{*}
\end{array}\right], A=\left[\begin{array}{cccc}
-c_{5} & 0 & 0 & 0 \\
0 & -c_{6} & 0 & 0 \\
0 & 0 & -c_{7} & 0 \\
-c_{5} \frac{x_{8}}{x_{7}} & -\frac{c_{6} C}{2 L_{o} x_{7}} & 0 & -c_{7}
\end{array}\right] \\
0 \\
0 \\
0 \\
g(x)=\left[\begin{array}{c}
C \\
\frac{C}{2 L_{o} x_{7}}\left(h_{2}(x)-\dot{y}^{*}\right)
\end{array}\right]
\end{gathered}
$$

Equation (78) defines a stable system and the vector $\left(z_{5}, z_{6}, z_{7}, x_{7}^{*}\right)$ converges exponentially fast to $(0,0$, $\left.0, \frac{C}{2 c_{7} L_{o} x_{7}} h_{2}(x)\right)$, whatever the initial conditions.

Proof. Equation (78) is obtained substituting the control law (66), (71) and (77) to $x_{6} u_{3}, x_{6} u_{4}$ and $x_{7}^{*}$ on the right side of (65), and (76). It is clear that the matrix $A$ is Hurwitz, this implying that the closed loop system (78) is globally exponentially stable. This completes the proof of Proposition 2.

\section{SIMULATION RESULTS}

The experimental setup is described by Fig. 3 and the nonlinear adaptive controller, developed in Section 3, including the control laws $(54,66,71,77)$ and the parameter adaptive law (53), will now be evaluated by simulation. 


\begin{tabular}{|c|c|c|c|}
\hline Characteristic & Symbol & Value & Unity \\
\hline Nominal power & $P_{N}$ & 1.5 & $\mathrm{Kw}$ \\
\hline Nominal stator voltage & $U_{s n}$ & 380 & $\mathrm{~V}$ \\
\hline Nominal stator current & $I_{s n}$ & 4.3 & $\mathrm{~A}$ \\
\hline Nominal flux & $\Phi_{s n}$ & 0.56 & $\mathrm{wb}$ \\
\hline Stator resistance & $R_{s}$ & 1.75 & $\Omega$ \\
\hline Stator inductance & $L_{s}$ & 0.295 & $\mathrm{H}$ \\
\hline Nominal rotor voltage & $U_{r n}$ & 225 & $\mathrm{~V}$ \\
\hline Nominal rotor current & $I_{r n}$ & 4.5 & $\mathrm{~A}$ \\
\hline Rotor resistance & $R_{r}$ & 1.68 & $\Omega$ \\
\hline Leakeage inductance & $M s r$ & 0.195 & $\mathrm{H}$ \\
\hline Rotor inductance & $L_{r}$ & 0.165 & $\mathrm{H}$ \\
\hline Inertia moment & $J$ & 0.35 & $K_{g} . m^{2}$ \\
\hline Friction coefficient & $F$ & 0.026 & N.m.s.rd ${ }^{-1}$ \\
\hline Number of pole pairs & $p$ & 2 & \\
\hline Table 1.Numerical
\end{tabular}

Table 1. Numerical values of considered doubly fed induction motor characteristics

The simulated system is given the following characteristics: . Supply network: is triphase $220 \mathrm{~V} / 50 \mathrm{~Hz}$

. $\mathrm{AC} / \mathrm{DC} / \mathrm{AC}$ converters: $L_{o}=15 \mathrm{mH} ; C=1.5 \mathrm{mF}$; modulation frequency $10 \mathrm{KHz}$.

- Doubly fed induction machine: it is a $1.5 \mathrm{KW}$ motor whose characteristics are summarized in Table 1.

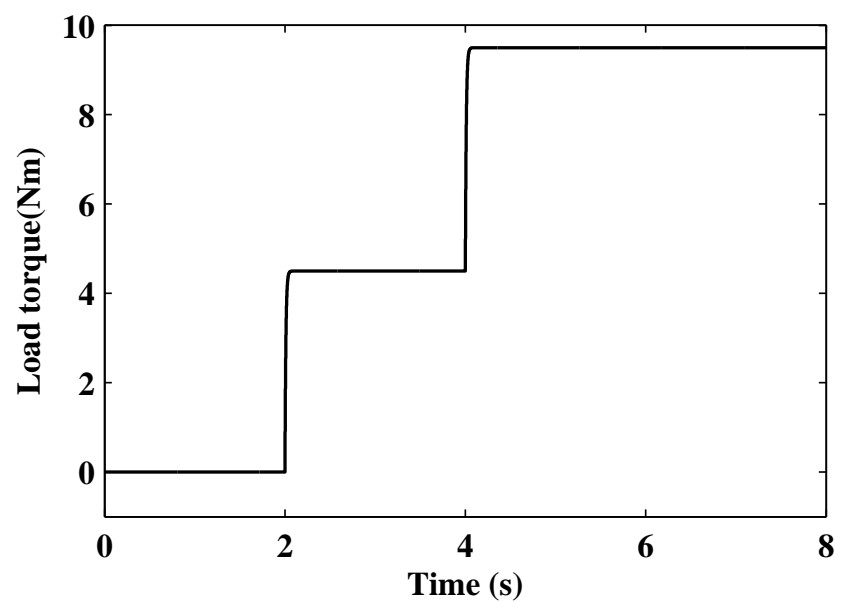

Fig. 4. Load torque $T_{L}(N . m)$

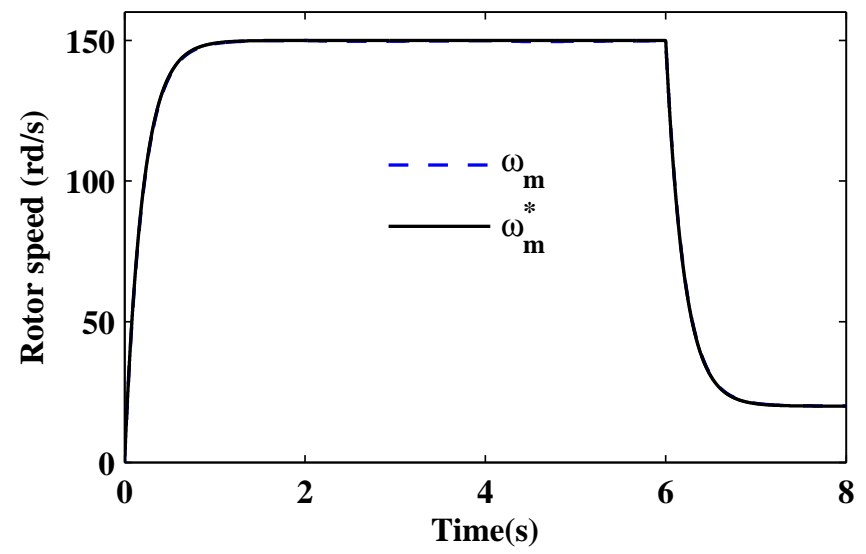

Fig. 5. Speed $\omega_{m}(r d / s)$

The simulation protocol is described by Figs. 4 and 5 which show that the reference signals and load torque, are profiled so that the machine is enforced to operate, successively, both at high and low speeds. Specifically, the machine operates in high speed $\left(\omega_{m}^{*}=150 \mathrm{rd} / \mathrm{s}\right)$ over the interval $[0,6 s]$ and at low speed $\left(\omega_{m}^{*}=10 \mathrm{rd} / \mathrm{s}\right)$ over $[6,8 s]$.

The DC-link voltage reference is set to the constant value $v_{d c}^{*}=220 \mathrm{~V}$. The reference value $\Phi_{s}^{*}$ for the stator flux norm is set to its nominal value $(0.7 w b)$.

The indicated values of design parameters $\left(c_{1}, c_{2}, c_{3}\right.$, $\left.c_{4}, c_{5}, c_{6}, c_{7}\right)$ have been selected using a try-and-error search method and proved to be suitable. The experimental setup is simulated within the Matlab/Simulink environment with a calculation step of $5 \mu \mathrm{s}$. This value is motivated by the fact that the inverter frequency commutation is $10 \mathrm{kHz}$. In the light of the closed-loop responses (see Figs 5 - 9), it is seen that the multiloop nonlinear adaptive controller meets all its objectives and enjoy quite satisfactory transient performances.

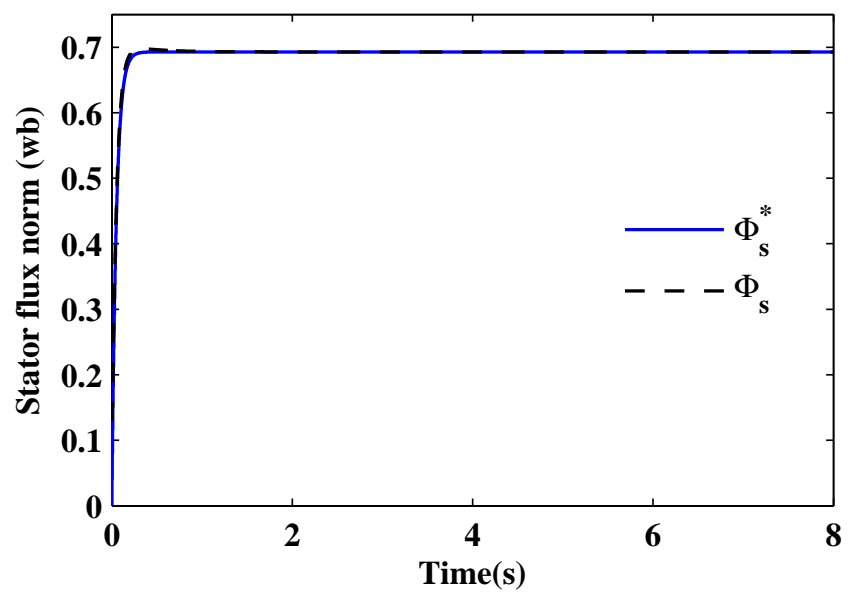

Fig. 6. Stator flux norm (wb)

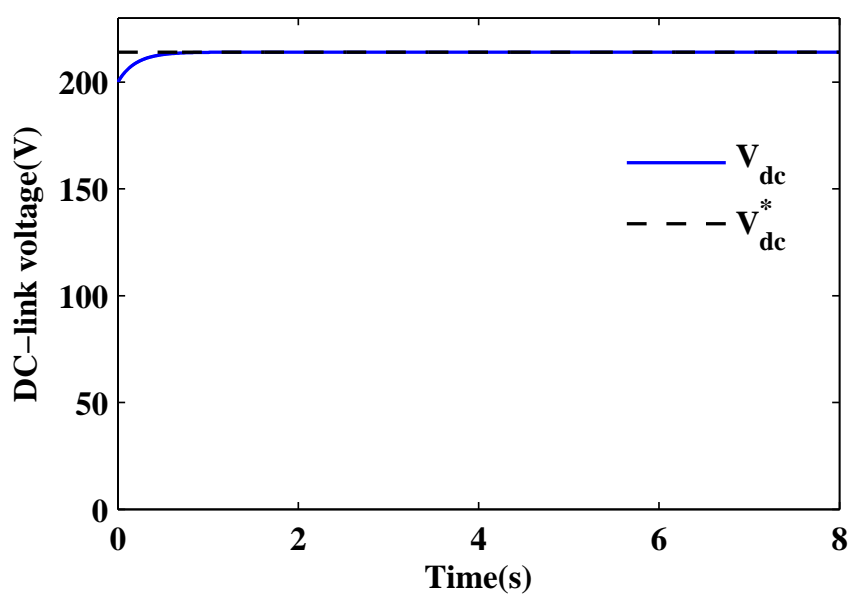

Fig. 7. DC-link voltage $v_{d c}(V)$

\section{CONCLUSIONS}

In this paper, the problem of controlling associations including $\mathrm{AC} / \mathrm{DC}$ rectifier, $\mathrm{DC} / \mathrm{AC}$ inverter and doubly fed induction motor has been addressed. The system dynamics 


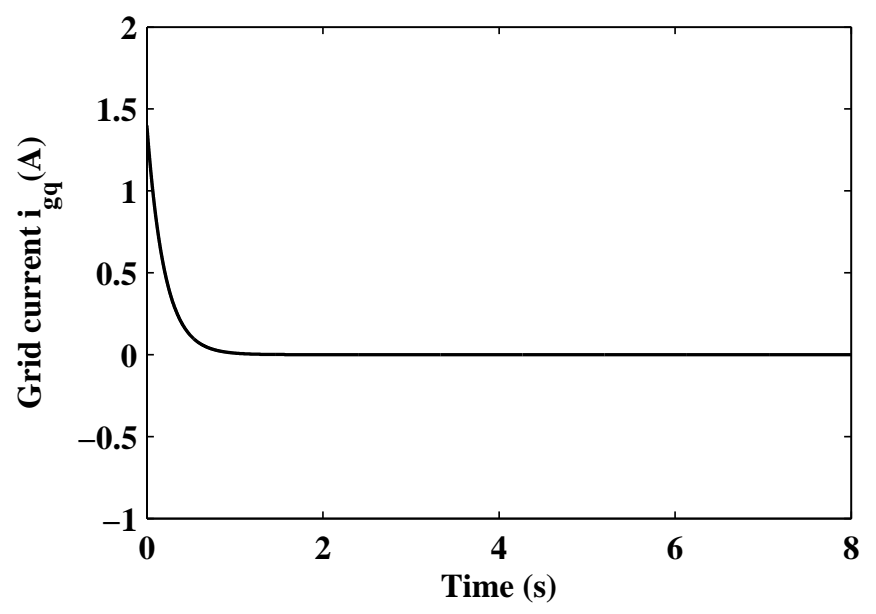

Fig. 8. Grid current $i_{g q}(A)$

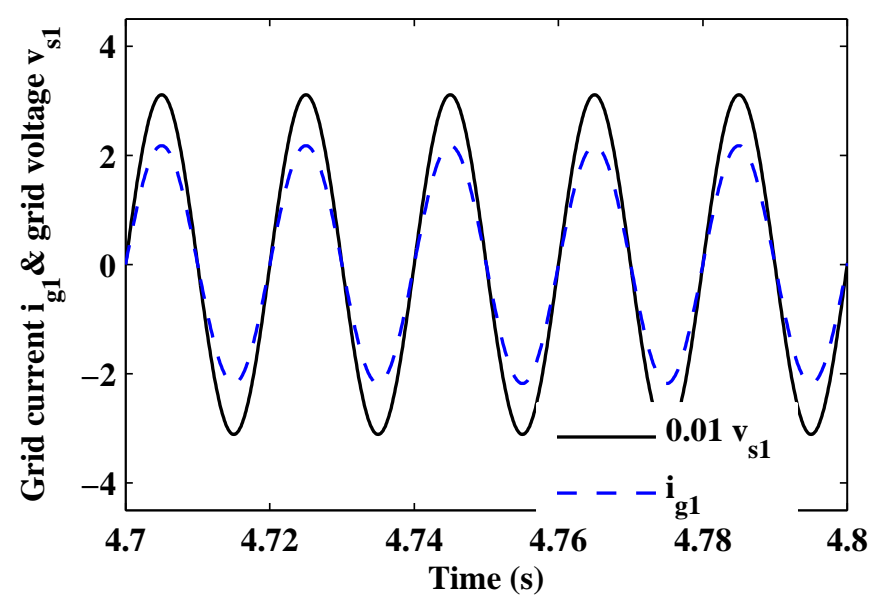

Fig. 9. Unitary power factor checking in presence of a varying speed reference and load torque

have been described by the averaged eighth order nonlinear state-space model (23-30). Based on such a model, an adaptive nonlinear controller defined by $(54,66,71,77$, 53), has been introduced for DFIM-AC/DC/AC converters association drives. The proposed controller is designed based on adaptive backstepping control approach and is capable of making the system states trajectories follow the speed reference signal with unity power factor condition inspite of external load torque disturbance. The proposed control approach has been tested for the motoring mode. Furthermore the DC link voltage is maintained constant also based backstepping control, using a rotating synchronous reference frame with $d$-axis coincide with the direction of space voltage vector of the main AC supply. Computer simulation results obtained, confirm the validity and effectiveness of the proposed control approach.

\section{REFERENCES}

B. Boukhezzar and H. Siguerdidjane. Nonlinear control with wind estimation of a DFIG variable speed wind turbine for power capture optimization. Energy Conversion and Management, volume 50, pages 885-892, 2009.

F. Bonnet, P.E. Vidal and M. Pietrzak-David. Dual direct torque control of doubly fed induction ma- chine. IEEE Transactions on Industrial Electronics, volume 54, pages 2482-2490, 2007.

P.E. Vidal, M. Pietrzak-David and F. Bonnet. Mixed control strategy of doubly fed induction machine. Elsevier - Verlag, Electrical Engineering, Archiv fur Electrotechnik, volume 90, pages 337-346, 2008.

G. Salloum ,R. Mbayed, M. Pietrzak-David and B. De Fornel. Loopshaping $H_{\infty}$ control for doubly fed induction motor. In Eurpean Power Electronics and Applications EPE.pages 1-9, 2007.

B. Hopfensperger, D.J. Atkinson and R.A. Lakin. Statorflux-oriented control of a Doubly-Fed Induction Machine with and without position encoder. IEEE Proc.-Electr. Power Appl, volume 147, 2000.

Y. Gritli, A. Stefanib, C. Rossib, F. Filippetti and A. Chattia. Experimental validation of doubly fed induction machine electrical faults diagnosis under timevarying conditions. Electric Power Systems Research, volume 81, pages 751-766, 2011.

H.B.M. Metwally, F.E. Abdel-kader, H.M. El-Shewy and M.M. El-Kholy. Optimum performance characteristics of doubly fed inductions motors oriented control. Energy Conversion and Management, volume 43, pages 3-13, 2002

A.G. Abo-Khalil. Synchronization of DFIG output voltage to utility grid in wind power system. Renewable Energy, volume 44, pages 193-198, 2012.

F. Poitiers, T. Bouaouiche and M. Machmoum. Advanced control of a doubly-fed induction generator for wind energy conversion. Electric Power Systems Research, volume 79, pages 1085-1096, 2009.

Z. Song, T. Shi, C. Xia and W. Chen. A novel adaptive control scheme for dynamic performance improvement of DFIG-Based wind turbines. Energy, volume 38, pages $104-117,2012$.

V. Verma, S. Maiti and C. Chakraborty. Grid-connected vector-controlled slip-ring induction machine drive with out speed sensor. Simulation Modelling Practice and Theory, volume 18, pages 984-997, 2010.

S. Peresadaa, A. Tillib and A. Toniellib. Power control of a doubly fed induction machine via output feedback. Control Engineering Practice, volume 12, pages 41-57, 2004.

S. Khojet El Khil, I. Slama-Belkhodja, M. Pietrzak-David and B. De Fornel. Power distribution law in a Doubly Fed Induction Machine. Mathematics and Computers in Simulation, volume 71, pages 360-368, 2006.

J. Michael, D. Ryan, W. Rik. Modeling of sinewave inverters: A geometric approach. In Industrial Electronic Conference, IEEE Conference, pages 396 - 401, 1998.

M. Krstic, I. Kanellakopoulos and P. Kokotovic. Nonlinear and Adaptive Control Design. John Willey \& Sons, Inc, 1995 .

H. Khalil. Nonlinear Systems. Prentice Hall, NJ, USA.

D. Xiying and W. Jian. A new control strategy of doubly fed induction machine for hybrid electric vehicle. In International Conference on Computer, Mechatronics, Control and Electronic Engineering (CMCE), pages 6063,2010 . 